\title{
«SI UNA MUJER TIENE LA CABEZA GRANDE»: FISIONOMÍA Y CARÁCTER FEMENINO EN UN TEXTO ASIRIOBABILÓNICO
}

\author{
Érica Couto Ferreira \\ Institut Universitari d’Història J. Vicens i Vives (Barcelona)
}

\section{RESUMEN}

El cuerpo humano en Mesopotamia era entendido como objeto adivinatorio: un sistema de signos, portador de mensajes sobre el propio individuo, cuyo significado debía decodificarse mediante la observación y la interpretación. Tomando como fuente principal de mi trabajo la serie fisionómica Šumma sinništu qaqqada rabât («Si una mujer tiene la cabeza grande»), analizo, por una parte, los mecanismos por los que se promueve una determinada visión de las mujeres en la adivinación fisionómica a partir de la lectura sexuada de su cuerpo. Por otra, los elementos que caracterizan esta imagen femenina, en base a dos grandes ejes: la imagen de la mujer ideal encarnada en el rol de madre; y los peligros que amenazan la vida de las mujeres en calidad de procreadoras.

PALABRAS CLAVE: Mesopotamia, Cuerpo femenino, Adivinación, Fisionomía.

\section{«IF A WOMAN HAS A BIG HEAD»: PHYSIOGNOMY AND FEMININE NA- TURE IN AN ASSYRO-BABYLONIAN TEXT}

\begin{abstract}
In Mesopotamia, the human body was understood as an object for divination, that is, a system of signs, which carried messages about the individual, and whose meaning had to be decoded by means of observation and interpretation. Taking the physiognomic series Summa sinništu qaqqada rabât («If a woman has a big head») as the main source of my article, I analyse, on the one hand, the processes that take part in the promotion of a particular perception of women based on a specific reading of the female body. On the other hand, I deal with the elements that characterize this female perception, basically, the image of the ideal woman centred on motherhood, and, in close relation to this, the dangers that threaten women's life during pregnancy.
\end{abstract}

KEY WORDS: Mesopotamia, Female Body, Divination, Physiognomy. 


\section{INTRODUCCIÓN}

Las técnicas adivinatorias desarrolladas en el área de Mesopotamia durante la antigüedad propiciaron una ingente producción de textos escritos que se han constituido en una de las fuentes principales para el conocimiento de los modos de representación y comprensión del universo. En estos textos, la práctica de la adivinación se revela como aspecto fundamental de la cultura mesopotámica, puesto que sirve a la tarea de conducir las vidas de los integrantes de toda la comunidad en todo tipo de contextos: político, militar, médico, personal, cotidiano. Los dioses, verdaderos artífices del destino humano, hacen llegar los mensajes a su creación a través de un código que precisa ser descifrado. La divinidad utiliza para ello un sistema de escritura que recurre a las realidades físicas, humanas y naturales, para expresarse. La variedad de elementos tomados como signos sobre los que realizar la predicción incluye, por tanto, todo tipo de realidades visibles: el aceite en la aleuromancia, el hígado de oveja en la hepatoscopia, los fenómenos celestes, el comportamiento de los animales, el nacimiento de fetos malformados, etc ${ }^{1}$.

El cuerpo humano, en este contexto, también era entendido como un signo portador de mensajes, y como transmisor de significados y actitudes socioculturales. La gestualidad y la expresión corporal servían a la tarea de comunicar, de modo que, por citar sólo algunos ejemplos, el abrir los puños, los brazos, o el levantar las manos indicaban súplica y plegaria, el inclinar la cabeza significaba sumisión, y el golpearse el pecho evidenciaba un profundo lamento de dolor ${ }^{2}$. También el estatus o la situación jurídica del individuo se imprimía en su apariencia física, de modo que determinados peinados evidenciaban la condición de esclavo ${ }^{3}$, por el contrario, revelaban la pureza del

1 Para profundizar en los múltiples aspectos de la adivinación en Mesopotamia, consúltese Maul, S.M. (2002-2005), Omina und Orakel. A. Mesopotamien. Reallexikon der Assyriologie, 10, Berlin \& New York, De Gruyter, 34-88; BotTÉRO, J. (1974), Symptômes, signes, écritures. En VERnANT, J.-P. (coord.), Divination et Rationalité, Paris, Éditions du Seueil, pp. 70-197; FARBER, W. (1995), Witchcraft, Magic and Divination in Ancient Mesopotamia. En SAsson, J. (coord.), Civilizations of the Ancient Near East- Volume III-IV, New York, Hendrickson Publishers, pp. 1895-1910.

2 GruBER, M.I. (1980), Aspects of Nonverbal Communication in the Ancient Near East, Roma, Biblicae Institute Press, analiza los diversos aspectos de la comunicación no verbal en el ámbito del Próximo Oriente antiguo, basándose en fuentes escritas hebreas, ugaríticas y acadias.

3 Para testimonios sobre la abbuttu (trenza o tipo de peinado impuesto como marca de esclavitud), véanse los siguientes ejemplos paleobabilónicos, extraídos de textos legales incluidos en V.V.A.A. (1956-), Chicago Assyrian Dictionary (CAD), Chicago, Oriental Institu- 
que ejercía como sacerdote ${ }^{4}$. Pero si la gestualidad y la apariencia física se constituyen en mecanismos de expresión voluntaria de significados y actitudes personales, sociales y culturales, existen otros ámbitos en los que el cuerpo se convierte en un transmisor involuntario de significados, un signo cuya lectura permitía discernir el destino trazado por los dioses para el curso de la vida. En este ámbito se inscribe la adivinación fisionómica, que revela los significados ocultos en los rasgos físicos del individuo.

Partiendo de la serie fisionómica «Si una mujer tiene la cabeza grande» (Šumma sinništu qaqqada rabât), quisiera proponer el análisis de un aspecto particular de la misma: por un lado, los mecanismos por los que se construye la imagen de la mujer próspera a partir de los rasgos físicos que se le atribuyen, y que, considerando la función para la que la serie fue compilada, hacen reconocible a la «esposa ideal»; por otro, el estrecho vínculo que se construye a lo largo del texto entre la imagen fisionómica y el rol reproductor femenino. La singularidad de este texto respecto al corpus de textos adivinatorios en general, y del conjunto de textos fisionómicos en particular, es el punto central que ocupa la fisionomía de las mujeres en la articulación del texto. El cuerpo femenino se convierte en representación del presente, en evidencia de la personalidad de las mujeres, y en el portador de su futuro. Un futuro que, por otra parte, se circunscribe al ámbito doméstico, al ejercicio de la maternidad, y a las posibilidades de supervivencia, y que ofrece una visión conscientemente limitada de lo que significaba ser mujer en Mesopotamia, por cuanto esta visión se construye exclusivamente a partir de la lectura e interpretación del cuerpo femenino, que en la serie se constituye como única fuente de conocimiento de las capacidades y defectos atribuidos a las mujeres.

te, vol. A/1 s.v. abbuttu, pp. 48-50: Laws of Eshnunna (LE) $§ 12$ A iv 8 y B iv 12 «no slave or slave girl of Eshnunna, who is marked with a kannu, a maškanu (en ambos casos, «grillete») or an abbuttu leaves the (city) gate of Eshnunna without the owner's (permission)»; LE §13 A iv 12 y B iv 16, «a slave or a slave girl who has entered the (city) gate of Eshnunna under the protection of an (official) messenger will be marked with a kannu, a maškanu and a abbuttu, so that he is safeguarded for his owner»; LE §146: 56 «due to the fact that she (the unsubmissive slave girl) has borne sons, her mistress cannot sell her, she puts an abbuttu on her and considers her (to be like) the (other) slave girls»».

4 Tómese como ejemplo la composición literaria «El hombre pobre de Nippur», en el que el protagonista, para hacerse pasar por médico, se afeita la cabeza. Véase FosTER, B. R. (1995), From Distant Days. Myths, Tales, and Poetry of Ancient Mesopotamia, Bethesda, Maryland, CDL Press, p. 360, líneas 114ss. 


\section{CARACTERÍSTICAS DE LA SERIE Šumma sinnišstu qaqqada rabât}

De la serie fisionómica Šumma sinništu qaqqada rabât $t^{5}$, cuya canonización data del siglo XI a.e.c., sólo nos han llegado algunos fragmentos: CT 51 153, K 9230, TBP 11a (K 12898), K 10511, BM 30209, BM 69492, junto a un último texto del que han sobrevivido varios manuscritos, permitiendo la reconstrucción parcial de la tablilla: K 8627+ (TBP 11b); K 6190+ (TBP11c); K 6675+ K608+; W 23286 (SpTu IV 149); VAT 9980+ (KAR 206+466); VAT 9973 (KAR 472). Este último fragmento, aunque incompleto, reúne 265 líneas y constituye, por tanto, el núcleo de datos imprescindible para el análisis y la interpretación de la serie. El texto fue publicado en su edición más reciente y completa por Barbara Böck, en el año 2000, e integrada en el volumen Die Babylonisch-Assyrische Morphoskopie ${ }^{6}$. Esta monografía presenta una cuidada edición de las distintas series de textos fisionómicos cuneiformes

5 Probablemente deba considerarse una subserie dentro de Alamdimmû, serie fisionómica donde el cuerpo del hombre es tomado como signo sobre el que realizar las predicciones. Muchas de las apódosis difieren respecto a aquellas registradas en los textos fisionómicos femeninos: aspectos vinculados al poder, a la vida de palacio, y a la relación del sujeto con el rey ejercen un notable protagonismo en el texto. Esto ha llevado a la conclusión, generalmente aceptada por la comunidad científica, de que el manual Alamdimmû se habría usado en el análisis fisionómico de los individuos de sexo masculino destinados al servicio del palacio, mientras el texto de «Si una mujer tiene la cabeza grande» se habría usado en el proceso de elección de esposa. En cuanto a los datos que sugieren la interpretación de la serie Šumma sinništu qaqqada rabât como parte de Alamdimmû, estos proceden, primero, del tratado de diagnósticos y pronósticos, y segundo, del catálogo de fuentes para el ejercicio de la ašipūtu (disciplina que engloba la práctica de ceremonias religiosas; rituales purificatorios, curativos, apotropaicos; ciertas técnicas adivinatorias, entre otros saberes). En lo que respecta al tratado de diagnósticos y pronósticos, sus contenidos se distribuyen y tratan de manera similar a los contenidos fisionómicos, pero tomando como signo los síntomas del cuerpo enfermo. Cuenta, además, con varias tablillas específicamente dedicadas a las enfermedades y síntomas de la mujer. En cuanto al catálogo de fuentes para la práctica de la ašipūtu, y publicado como KAR 44 , el texto «Si una mujer tiene la cabeza grande» no se menciona como serie per se en el apartado que cita los textos fisionómicos. Véase BotTÉRO, J. (1985), Le manuel de l'exorciste et son calendrier. En BotTÉro, J. (coord.), Mythes et rites de Babylone, Paris, Editions Champion, pp. 65-112; FinKEL, I.L. (1988), «Adad-apla-iddina, Esagil-kīn-apli, and the series SA.GiG». En LeICHTY, E. (coord.), A Scientific Humanist. Studies in Memory of Abraham Sachs, Philadelphia, Occasional Prublications of the Samuel Noah Kramer Fund, pp. 143-160; KinnieR-WiLson, J.V. (1964), The Nimrud Catalogue of Medical and Physiognomical Omina. Iraq, 24, 52-62.

6 Böck, B. (2000), Die babylonisch-assyrische Morphoskopie, Viena, Institut für Orientalistik der Universität Wien. 
que han sobrevivido al paso del tiempo, e incluye un amplio estudio preliminar de los mismos.

La adivinación fisionómica se basa en la determinación de los rasgos morales y comportamentales presentes, o bien de las tendencias para el futuro, a partir de la interpretación de las características y particularidades de las diferentes partes del cuerpo del individuo observado. Dicha lectura e interpretación se enuncia, en su formulación en los textos cuneiformes, a través de una prótasis, en la que se describe el signo a interpretar, el «hecho» o el rasgo que caracteriza la realidad, seguido de una apódosis, esto es, el significado o la interpretación dada al signo:

«si (la mano) es pequeña (prótasis)= será pobre (apódosis)»»;

«si sus sienes, (tanto) la derecha (como) la izquierda, le duelen, sus ojos, (tanto) el derecho (como) el izquierdo, están cubiertos por una sombra (prótasis) $=$ este hombre ha blasfemado contra su dios o contra el dios de su ciudad (...) (apódosis) $\rangle^{8}$.

En los textos fisionómicos, las entradas se organizan en base a los contenidos de la prótasis, comenzando por aquellas que se refieren a la cabeza y siguiendo en orden descendente hacia los pies. Por el estado fragmentario en el que se encuentran las evidencias textuales, las primeras líneas identificables en el texto más largo hacen referencia a las orejas, y las entradas siguen: barbilla y otras partes del rostro (en algunos casos, difíciles de identificar de modo concreto por los daños en la tablilla); axilas, manos y brazos; tórax y pecho; pelvis, vientre y cadera; muslos, piernas y dedos. Este sistema narrativo del cuerpo a capite ad calcem es una constante en los textos cuneiformes de contenido anatómico, como lo demuestran la lista lexical paleobabilónica Ugu-mu, y los textos de diagnósticos y pronósticos ${ }^{9}$.

El estado fragmentario de nuestro texto hace que la totalidad de los contenidos se vuelva inaccesible. En el fragmento CT 51153 no hay ninguna entrada completa, al igual que en K 9230, K10511, BM 30209, у BM 69492.

7 BöcK (2000), p. 157, línea 103.

8 Ejemplo tomando de un texto diagnóstico. Véase LABAT, R. (1951), Traité de diagnostics et prognostics medicaux, París, Académie Internationale d'Histoire des Sciences, pp. 3637, línea 29.

9 Civil, M. (1967), Series ugu-mu. En Landsberger, B. (coord.), Materialien zum Sumerischen Lexicon, Roma, Pontificium Institutum Biblicum, pp. 49-73; LABAT (1951); HeESSEL, N.P. (2000), Babylonisch-Assyrische Diagnostik, Münster, Ugarit-Verlag. 
Incluso en el caso del texto más íntegro, anteriormente mencionado, en un gran número de entradas la prótasis o la apódosis están dañadas, lo que incrementa la dificultad para reconstruir los mecanismos que establecen la relación entre signo y predicción. A pesar de ello, pueden apuntarse algunas tendencias de la semiótica dominante en el corpus textual adivinatorio. Entre las constantes que se observan en los textos, pueden citarse las siguientes correspondencias:

a) en partes del cuerpo «dobles» (ojos, manos, brazos), o especificando derecha-izquierda de una misma parte, las apódosis de ambas entradas serán antagónicas entre sí. Por ejemplo, si en nuestro texto se describe lo siguiente en una entrada: «si (los dedos del pie) son largos, no tendrá éxito ${ }^{10}$, lo que se especifica en la entrada siguiente será: «si los dedos del pie son cortos, tendrá éxito, será sana» ${ }^{11}$. Esto prueba la creencia en que la cualidad contraria a aquella especificada en el primer ejemplo (en este caso, dedos cortos frente a dedos largos) se traduce, igualmente, en una apódosis de significado opuesto a la misma («tendrá éxito», en contraposición al «no tendrá éxito» de la primera profecía mencionada) ${ }^{12}$.

b) grande/ abundante/ largo- pequeño/ escaso/ corto en la prótasis suele traducirse con imágenes de bienestar/ fortuna o carencia/ infortunio, respectivamente, en la apódosis. Por ejemplo: «si su brazo es muy grueso $=$ está favorecida por un dios» ${ }^{13}$; «si (su brazo) es pequeño $=$ tendrá preocupaciones» ${ }^{14}$; «si (su mano) es larga= será rica, está favorecida por el dios» ${ }^{15}$; «si (su mano) es corta $=$ será pobre ${ }^{16}$. Sin embargo, esta correspondecia se invierte cuando se estima perjudicial o negativo (en base a consideraciones y valores culturales no siempre evidentes para el investigador o la investigadora) que una determinada parte del

10 BöcK (2000), pp. 158-159, línea 120.

11 BöcK (2000), pp. 158-159, línea 121.

12 Esta dualidad se utiliza para expresar un fenómeno de complementariedad: el binomio se vuelve imprescindible para que pueda existir «lo completo» (la derecha requiere la izquierda; lo alto exige la existencia de lo bajo, etc). Véase Koch-Westenholz, U. (2002), Everyday Life of Women According to First Millenium Omen Apodoses. En PARPOLA, S. W. (coord.) Sex and Gender in the Ancient Near East, Helsinki, The Neo-Assyrian Text Corpus Project, pp. 301-09, p. 303.

13 BöcK (2000), pp. 158-159, línea 94.

14 BöcK (2000), pp. 158-159, línea 95.

15 BöCK (2000), pp. 158-159, línea102.

16 BöcK (2000), pp. 158-159, línea 103. 
cuerpo sea grande, gruesa o larga. Por ejemplo, podemos citar de nuevo el binomio «si (los dedos del pie) son largos, no tendrá éxito»; «si los dedos del pie son cortos, tendrá éxito, será sana».

Desafortunadamente, este conjunto de textos presenta numerosos problemas de interpretación. Al ser parte integral del conjunto de la tradición escrita asiriobabilónica, ha permanecido enquistado durante siglos. Es decir, copiado y recopiado periódicamente por los escribas de cuyo currículum formó parte, este Šumma sinništu qaqqada rabât difícilmente recoge los cambios que, a lo largo de la historia mesopotámica, se hayan podido producir en el estatus real de las mujeres. Los diferentes tipos de condición y nivel social al que podían pertenecer las mujeres, su adscripción a determinadas clases sacerdotales, a la servidumbre o a la esclavitud, el ejercicio de actividades comerciales y económicas, etc, permanecen ausentes del texto, y sus contenidos parecen encaminarse únicamente a determinar el perfil de la madre y compañera ideales. Este texto fisionómico representa a la mujer como un elemento base de la articulación familiar y social, independientemente de la extracción socioeconómica y de las implicaciones de ésta en el curso vital de las mujeres. Se parte de la base de que, sean ricas o pobres, miembros de la elite o trabajadoras, llegará el día en que deban ejercer como madres y esposas, y este es el punto que se enfatiza en el texto. Este Šumma sinništu qaqqada rabât, siendo parcial y sesgado, permite, sin embargo, una aproximación a las características, roles y aspectos vitales considerados «propiamente femeninos», roles presentados como inmutables, establecidos culturalmente y ajenos a cambios sociales, políticos o jurídicos.

\section{LECTURA FISIONÓMICA DEL CUERPO FEMENINO}

Como mencioné en la introducción a la serie, la prótasis es la parte de la profecía que contiene el signo a interpretar, y en la que se describen las características de la parte del cuerpo en cuestión (cabeza, manos, vientre, pecho, etc). Las apódosis proporcionan información diversa sobre la mujer consultada. Por un lado, se determinan aspectos que podríamos considerar individuales o personalistas, relevantes para la mujer como sujeto ${ }^{17}$ :

a) su curso vital: vivirá, morirá, sus días serán largos, fin de sus días.

17 Para una relación completa de estos elementos, véase BöcK (2000), pp. 36-38. 
b) incidencias vitales: si gozará de satisfacciones o de insatisfacciones, si vivirá penalidades o en plenitud, si padecerá pobreza o riqueza, como en el ejemplo «si sus dedos son largos= construirá una casa, llegará a anciana, es una mujer afortunada ${ }^{18}$.

c) rasgos de carácter: manirrota ${ }^{19}$, sincera ${ }^{20}$, depresiva ${ }^{21}$, bruja $a^{22}$, orgullo$\mathrm{sa}^{23}$, atormentadora ${ }^{24}$, etc.

Por otro lado, se formulan predicciones que atañen a las mujeres como protagonistas en la vida familiar:

a) el curso de su matrimonio (por ejemplo, si será viuda), o la suerte que correrá la casa, es decir, el linaje del marido en el que se integrará al contraer matrimonio. La expresión utilizada con mayor frecuencia para indicar esta transferencia es «la casa en la que entra» o «la casa en la que vive», y a pesar de que en la mayoría de casos las prótasis permanecen incompletas, las apódosis hacen una clara referencia a esto ${ }^{25}$. Por ejemplo, en la línea 121 se especifica «si los dedos (de su mano) son cortos $=$ empobrecerá la casa en la que entra».

b) su relación con la maternidad y la sexualidad (curso del embarazo, fecundidad, infidelidad, etc). Este último aspecto, que subraya el papel de las mujeres como esposas y madres, destaca importantemente en el texto, y merece por ello una especial atención.

18 BöcK (2000), pp. 166-167, línea 233.

19 BöcK (2000), pp. 152-153, línea 4.

20 BöcK (2000), pp. 152-153, línea 5.

21 El término $\mathrm{ZARAH}_{2}$ utilizado en el texto equivale al acadio nissatu, «preocupación, sufrimiento, depresión, tristeza». Véase CAD, N/2 s.v. nissatu A, pp. 274-275.

22 En el texto se registran tres ejemplos, BöcK (2000), pp. 158-159, líneas 126, 131 y 133. Para una mayor profundización en la imagen de la mujer como bruja, véase SEFATI, Y.; y KleIN, J. (2002), The Role of Women in Mesopotamian Witchcraft. En PARPOLA, S. W. (coord.), Sex and Gender in the Ancient Near East, Helsinki, The Neo-Assyrian Text Corpus Project, pp. 569-587; ABUSCH, T. (2002), Mesopotamian Witchcraft. Towards a History and Understanding of Babylonian Witchcraft Beliefs and Literature, Leiden, Brill-Styx.

23 BöcK (2000), pp. 148-149, línea 4.

24 ВöcK (2000), pp. 156-157, líneas 101 y 112; ВöcK (2000), pp. 158-159, línea 132.

25 Las entradas en las que se alude a este aspecto figuran en BöcK (2000), pp. 154-155. 


\subsection{Un aspecto concreto: la representación de la mujer próspera}

Nuestro texto nos provee, a través de las descripciones fisionómicas de las prótasis, el perfil, aunque incompleto y parcial, de la mujer próspera y afortunada. Este perfil, como intentaré argumentar aquí, se traduce en un modelo, en un físico femenino concreto, que se asocia estrechamente a una caracterización de las mujeres como elemento fundamental en la articulación familiar a través de la procreación y de la maternidad. En Šumma sinništu qaqqada rabât, ciertos rasgos asociados al cuerpo femenino sirven para construir la imagen de mujer afortunada. Esta imagen se elabora a partir de binomios significativos, como apunté más arriba: una misma parte del cuerpo porta un significado positivo cuando la cualidad o el estado que se le atribuye se considera fasta o beneficiosa, y un significado negativo cuando sucede lo contrario. De este modo, la imagen de la mujer próspera se dibuja en el texto de la siguiente manera:

a) Pecho abundante- pecho pequeño

En las líneas 143 y 144 se especifica, respectivamente:

«si la mujer tiene el pecho grueso (variante «anormalmente grueso») $=$ será recta, es una mujer del dios»;

pero

«si la mujer tiene el pecho pequeño $=$ será traidora, promiscua» ${ }^{26}$.

De un modo similar, en las líneas 156 y 157, respectivamente, se recoge lo siguiente:

«si los pechos son anormalmente gruesos= será una mujer de dios»;

«si los pechos son pequeños= está destinada a la escasez o a la privación».

Bajo la expresión «mujer de dios» ${ }^{27}$ se indica a una persona favorecida por el dios, próspera, afortunada, o bien que posee un dios que la protege. De los ejemplos citados se deduce que el pecho grande se asocia con la suerte y la fortuna, mientras que el pecho pequeño denota carencia (tanto de medios como de moral) e infortunio.

26 BöcK (2000), pp. 158-159, línea 144. El texto utiliza el estativo nâkat, cuya traducción literal sería «(es una persona que) tiene relaciones sexuales (ilícitas)». Véase CAD N/1 s.v. $n a ̂ k u$, pp. 197-198.

27 En el texto, DingIR-na-at= ilānat. Véase CAD I s.v. ilānītu., p. 70; CAD I s.v. ilu 5, pp. 101-102. 
b) Pecho caído- pecho puntiagudo

En el binomio formado por las líneas 158 y 159 se estipula que el pecho caído indica que la mujer es fecunda (línea 158), significado establecido, probablemente, a partir de la referencia a la mujer que ha pasado por varios embarazos y que, habiendo amamantado a sus hijos, sufre la caída del pecho. Mientras que, por el contrario, el pecho puntiagudo indica que la mujer es infecunda (línea 159) ${ }^{28}$.

c) Pezones pequeños- pezones gruesos

«Si (los pezones) son pequeños= es una mujer de dios, una persona afortunada». Por el contrario:

«Si (los pezones) son demasiado gruesos= traerá la ruina»;

$\mathrm{y}$

«Si los pezones son anchos= padecerá insatisfacción» ${ }^{29}$.

El hecho de que los pezones anchos se tomen como un signo negativo se explicaría, según mi punto de vista, por la función que, en el contexto maternal, ejercen en la nutrición del bebé. Dado que es la parte del cuerpo que nutre, que da, que proporciona la fuente de alimentación para el neonato, si resulta demasiado amplio, como la boca de una fuente por la que el agua fluye, podría entenderse que una parte de la leche materna, del alimento (= riqueza, abundancia), podría perderse o malgastarse. $\mathrm{Si}$ esta relación simbólica que hipotetizo se probase cierta, explicaría por qué en este caso lo ancho o grueso conlleva una apódosis negativa.

d) Genitales largos- genitales cortos

En la línea 201 se apunta que la mujer que posee genitales largos, es una mujer de dios, mientras que en la línea consecutiva los genitales cortos auguran que la mujer vivirá con pérdidas o daños.

e) Labios de la vulva gruesos- labios de la vulva pequeños

Continuando con la línea trazada en el comentario anterior, en la línea $209^{30}$, los labios de la vulva gruesos se interpretan como signo de fortu-

28 Las líneas 161 y 162 presentan ciertas dificultades a la hora de interpretarlas bajo la misma perspectiva. La línea 161 indica «si tiene el pecho derecho largo, es infecunda», mientras que la línea 162 indica «si el pecho (UBUR, variante DIB.DIR.ŠI) izquierdo es largo (GíD.DA)= es fecunda». El porqué de esta distinción de significados resulta, a mi modo de ver, oscura.

29 BöcK (2000), pp. 162-163, líneas 175, 174 y 173 respectivamente.

30 BöcK (2000), pp. 164-165. 
na y prosperidad para la que es «mujer de dios». Por el contario, los labios de la vulva pequeños predicen dificultades en el parto ${ }^{31}$.

f) Trasero/ nalgas abundante(s)

En la línea 205 se explicita que, si el trasero ${ }^{32}$ es grueso, abundante, significa que la mujer en cuestión está favorecida por un dios. Desafortundamente, la línea 206, en la que se trata la predicción para las nalgas pequeñas, está incompleta, de modo que, desconociendo su apódosis, impide la comparación.

g) Caderas muy gruesas- caderas pequeñas

Prosiguiendo con este sistema de análisis, la línea 210 especifica: «si tiene las caderas muy gruesas, es una mujer de dios».

Pero:

«si las caderas son pequeñas, esa mujer tendrá preocupaciones» ${ }^{33}$.

En esta descripción de la mujer próspera puede incluirse, igualmente, la línea 194a:

«si la parte inferior del abdomen es extenso/ ancho= es fértil/ dará a luz».

Tomando conjuntamente todos estos datos, se observa que la mujer afortunada porta su buena suerte representada en el cuerpo, y esta fortuna se traduce en una constitución física representada por sus pechos gruesos, sus caderas anchas, sus genitales marcados, sus nalgas prominentes. En vista de esta caracterización, parece plausible afirmar que lo que aquí se muestra es una imagen de la fortuna basada en la capacidad reproductiva de las mujeres. Esta descripción, por otra parte, evoca casi inmediatamente la iconografía femenina visible en las figurillas tradicionalmente denominadas «venus», que se remontan al Paleolítico y que, con sus grandes pechos colgantes, el vientre abultado, las caderas anchas, y el pubis marcado, son comunes a muchas culturas (véase fig. 1) 34 . Conviene remarcar que cualquier intento de relacionar,

31 En el texto, mu-lam-mi-na-at, participio D de lamānu: «hacer desfavorable, hacer daño, causar problemas». Véase CAD L, s.v. lemēnu, pp. 116-119.

32 En el texto, ar-ka-ta-šá= (w)arkatu: «espalda, parte trasera». Véase CAD A/2, s.v. arkatu 1., pp. 274-276.

33 BöCK (2000), pp. 158-159, línea 144.

34 Bolger, D. (1996), Figurines, Fertility, and the Emergence of Complex Society in Prehistoric Cyprus. Current Anthropology, 37(2), 365-373; MCCOID, C. H.; y MCDERMOTT, L. 
directa o indirectamente, estas dos fuentes tan alejadas cronológica y culturalmente, haciendo derivar la una de la otra, o proponiendo un criterio común en la elaboración de texto escrito y representación iconógrafica, resulta poco fundamentado y no es, en ningún caso, el propósito de este artículo. Sin embargo, si estas figuras femeninas se toman, dejando a un lado los posibles significados concretos en la cultura de producción, como imágenes en las que se enfatizan los rasgos físicos propios de la mujer encinta, se observa que la fisionomía del embarazo es tomada como elemento transmisor de significados culturales y sociales en muy diversas culturas de la antigüedad ${ }^{35}$. Según propone Bahrani ${ }^{36}$ en relación a este tipo iconográfico, estas figuras pondrían énfasis en las capacidades reproductivas femeninas, dejando a un lado otros aspectos del cuerpo. Como en el propio texto fisionómico, la mirada que se proyecta sobre la mujer es conscientemente limitada: el mensaje que quiere transmitirse o la funcionalidad que se le atribuye bascula en torno a un elemento concreto, una parte del complejo entramado de características y roles que conforma a las mujeres en el contexto social.

\subsection{Los peligros de ser madre}

En el texto se interpretan, igualmente, los rasgos físicos que auguran un determinado desarrollo del embarazo, una vez que la mujer esté encinta, evidenciando la realidad de la mujer fértil que se concreta en la génesis y crianza del bebé (fig. 2). Una buena parte de las referencias hechas a este respecto aluden a la pérdida del bebé, suceso que suele describirse con la expresión «su embarazo no acabará» o «no completará su embarazo». Los rasgos físicos que auguran tal devenir son:

D. (1996), Toward Decolonizing Gender: Female Vision in the Upper Paleolithic. American Anthropologist, 98(2), 319-326; MCDERMOTT, L. (1996), Self-Representation in Upper Paleolithic Female Figurines. Current Anthropology, 37(2), 227-275; HACHUEL FERNÁNDEZ, E.; SANAHUja YLL, M. E. (1996), Diferenciación sexual y su expresión simbólica en algunos grupos arqueológicos del Paleolítico Superior. Duoda, 11, 61-76.

35 Véase el artículo de BATtini, L. (2006), Les images de la naissance en Mésopotamie. En Battini, L.; y Villard, P. (coord.), Médecine et médecins au Proche-Orient ancien. Actes du Colloque International organisé à Lyon les 8 et 9 novembre 2002, Maison de l'Orient et de la Méditerranée, Oxford, BAR International Series 1528, pp. 1-37, para un análisis de la representación de mujeres dando a luz en los cilindro-sellos mesopotámicos.

36 BAHRANI, Z. (2001), Women of Babylon. Gender and Representation in Mesopotamia, London, Routledge, p. 46. 
a) los pezones, cuya coloración transmite los siguientes significados: si son blancos, amarillos, negros, oscuros o pequeños ${ }^{37}$, la mujer no llegará a dar a luz.

b) el ombligo, que, cuando es duro, implica bien dificultades en el parto ${ }^{38}$, bien un embarazo truncado ${ }^{39}$.

Si se constrastan los contenidos de la serie fisionómica con aquellos de las tablillas 35 y 36 de la serie de diagnósticos y pronósticos ${ }^{40}$, cuya temática gira en torno a la mujer encinta, se registran algunas similitudes. En la tablilla 35 de dicha serie ${ }^{41}$, se especifica:

«si la cabeza del ombligo de la (futura) madre está suelta/ libre/ desata$\mathrm{da}=$ llevará a término su embarazo/ dará a luz a la criatura».

Estas dos referencias al «ombligo duro» y al «ombligo suelto o desatado» se relacionan con la simbología mesopotámica del embarazo:

«En las aguas del océano, temibles, violentas,

En el agua del mar lejano,

Está el pequeño, ¡sus brazos están atados!

Allí dentro, donde el ojo del sol no puede llevar la claridad, Asalluhi, el hijo de Enki, lo vio.

Aflojó sus apretados nudos,

37 BöcK (2000), pp. 160-161, líneas 163, 164, 165, 166 y 168. En la línea 169 se añade: «si tiene los pezones abollados/ hundidos= su embarazo no terminará (variante infecunda)»

38 BöcK (2000), 162-163, línea 188.

39 Böck (2000), 162-163, línea 190. La línea 189 presenta dificultades, puesto que describe «si su ombligo está blando= su embarazo no finalizará», contradiciendo, aparentemente, las bases de funcionamiento de los textos adivinatorios.

40 LABAT (1951), pp. 200-217. La serie SA.GIG/ sakikku, también llamada «de diagnósticos y pronósticos», reúne 40 tablillas de contenido médico, cuyo texto fue canonizado a mediados del siglo XI a.e.c. En cada una de las entradas, la prótasis describe uno o varios síntomas en el paciente, aunque también se consideran otros signos significativos en la diagnosis de la enfermedad, tal que su duración, el momento del día, o la situación en la que se contrajo el mal. La apódosis suele especificar la causa de dicha sintomatología, junto con la futura evolución de la enfermedad, y, en algunas ocasiones, incluso se sugieren remedios terapéuticos. Entre los contenidos de la serie conviene destacar la existencia de una subserie en las que el pronóstico trata el embarazo, la observación de las enfermedades que se desarrollan durante la gestación, además de la descripción de síntomas de enfermedades femeninas y de enfermedades infantiles.

41 LABAT (1951), pp. 208-209, línea 85. 
Lo puso en la senda,

Le abrió el camino» ${ }^{42}$.

El bebé se concibe como una entidad que vive atada al cuerpo de la madre. Para que no se produzcan complicaciones en el momento del parto, el «nudo» que le mantiene unido debe desatarse, de modo que el proceso de nacimiento llegue a buen término ${ }^{43}$, de ahí que el ombligo desatado se considere un signo positivo como augurio de un buen parto, frente al ombligo endurecido.

Otras entradas de la serie fisionómica ligadas al curso del embarazo especifican: «si su barriga se mantiene» ${ }^{44} \mathrm{o}$ «si los labios de la vulva son pequeños $\rangle^{45}=\langle$ «la mujer tendrá dificultades en el parto». En el primer caso, seguramente se alude a una prolongación excesiva del tiempo de embarazo, quizás ligada a problemas en la dilatación; en el segundo, los labios pequeños se vinculan a la idea de que un espacio demasiado estrecho impedirá la salida del bebé.

Varias referencias sobre el grado de fecundidad-infencudidad y del éxitofracaso en el término del embarazo, ligadas a la forma del ombligo, se especifican entre las líneas 191 y $197^{46}$. En la línea 191 se mantiene:

«si su ombligo está torcido hacia la derecha= su embarazo no acabará (variante no concebirá)»;

pero en la línea 192:

«si su ombligo se tuerce hacia la izquierda= su embarazo finalizará».

42 Traducción hecha a partir de un encantamiento para facilitar el parto, publicado en FOSTER (1995), p. 394:

«In the ocean waters, fearsome, raging,

In the water of the far-off sea,

There is the little one, his arms are bound!

There within, where the sun's eye cannot bring brightness,

Asalluhi, Enki's son, saw him.

He loosed his tight-tied bonds,

He set him on the way,

He opened him the path».

43 Para ejemplos de encantamientos para facilitar el parto que representan al feto como atado a la madre, véase STOL, M. (2000), Birth in Babylonia and the Bible. Its Mediterranean Setting, Groningen, Styx.

44 BöcK (2000), pp. 156-157, línea 104.

45 BöcK (2000), pp. 164-165, línea 209.

46 BöcK (2000), pp. 164-165. 
En consonancia con esto, la línea 86 de la tablilla 35 de la serie de diagnósticos y pronósticos ${ }^{47}$ expone:

«si (la cabeza de su ombligo) está torcida/ retorcida, suelta= el hijo que lleva no vivirá».

Algunas de las entradas de los diagnósticos y pronósticos vinculados a los síntomas de la mujer embarazada recuerdan más a la adivinación fisionómica que a la diagnosis médica: no hay mención a síntomas ni a males, sino que la condición presentada por las diversas partes del cuerpo sirven para determinar o el sexo del bebé, o el curso del embarazo, o incluso el futuro del hijo que está por nacer. Por ejemplo, en la tablilla 35 de la serie de diagnósticos y pronósticos, la línea 36 especifica:

«Si (los pezones) tiene(n) tres orificios/ perforaciones: el hijo que lleva será pobre».

La línea 37 continúa: «si tiene(n) cuatro orificios= la criatura que lleva será pobre».

La línea 38:

«cinco orificios= el bebé morirá»,

y así sucesivamente.

Estos dos textos (la serie Šumma sinništu qaqqada rabât y las tablillas 35 y 36 de la serie de diagnósticos y pronósticos) refieren dos momentos diferentes de la vida de las mujeres: la adivinación fisionómica parece aludir a la etapa fundacional de la familia y a la realización del matrimonio ${ }^{48}$, especificando las capacidades femeninas potencialmente significativas para el desarrollo de esta fase vital. Por el contrario, los diagnósticos y pronósticos muestran ya a la mujer encinta que debe enfrentarse a una serie de problemas prácticos vinculados a su embarazo (enfermedades, peligros de aborto, determinación del sexo del bebé, etc). Puede concluirse, por tanto, que ambos textos comparten una fase evolutiva intermedia en la que se explicitan, en uno y otro caso, los peligros de la maternidad. Los textos fisionómicos lo hacen recogiendo profecías en previsión del futuro a medio plazo, para cuando la mujer se una en matrimonio y reste encinta. La serie de diagnósticos y pro-

$47 \quad$ LABAT (1951), pp. 208-209.

48 Las hipótesis propuestas hasta el momento apuntan que este texto fisionómico debió usarse como una guía a la hora de elegir esposa, según Koch-WeSTENHOLZ (2002), p. 308. Eso podría explicar la imagen femenina que se construye en la serie, centrada en los vicios y virtudes personales, las capacidades para procurar la prosperidad a la familia del esposo, y el potencial reproductivo. 
nósticos, sin embargo, lo hace aludiendo al futuro inmediato de la mujer que, ya embarazada, dará a luz en breve término.

\section{CONCLUSIONES}

Otros modelos o facetas de la feminidad que sí se registran en otras fuentes no se reflejan en este texto: la mujer sensual de las poesías sumerias, la mujer trabajadora cuya asignación por el trabajo realizado se hace constar en listas de redistribución de alimentos, el personal de culto, las mujeres de la elite, las representaciones iconográficas erotizantes, las divinidades femeninas, etc, no tienen cabida en este Šmma sinništu qaqqada rabât ${ }^{49}$.

Si la serie constituye verdaderamente un manual para ayudar en la elección de esposa, como ha admitido buena parte de la comunidad científica, lo que se manifestaría en el texto es una voz masculina que codifica, lee e interpreta, desde una perspectiva propia, el cuerpo de las mujeres ${ }^{50}$. Y en esa lectura, las partes cuya fisionomía se toma como relevante en el proceso adivinatorio coinciden, en gran medida, con aquellas asociadas a la sexualidad y a la función reproductiva de las mujeres, o las que se ven alteradas durante el embarazo. La relación entre cuerpo y género sería, por tanto, biológica, por cuanto

49 Para una aproximación a estos y a otros aspectos, véase EBELING, E. (1971), Frau. Reallexikon der Assyriologie, 3, Berlin, De Gruyter, 100-104; CAMERON, A.; y KuHRT, A. (coord.), (1983), Images of Women in Antiquity, London \& Canberra, Croom Helm; DuRAND, J.-M. (coord.), (1987), La femme dans le Proche-Orient antique, Paris, Editions Recherche sur les Civilisations; Westenholz, J.G. (1990), Towards a New Conceptualization of the Female Role in Mesopotamian Society. Journal of the American Oriental Society, 110, 510-21; AsHER-Greve, J.M. (1997), Feminist Research and Ancient Mesopotamia: Problems and Prospects. En Fontaine, A.B.C. Fontaine (coord.), A Feminist Companion to Reading the Bible, Sheffield, Academic Press, pp. 218-37; Asher-Greve, J.M. (1998), The Essential Body: Mesopotamian Conceptions of the Gendered Body. En WyKe, M. (coord.), Gender and the Body in Ancient Mediterranean, Oxford \& Malden, Blackwell Publishers, pp. 8-37; GuINAN, A.K. (1998), Auguries of Hegemony: The Sex Omens in Mesopotamia. En WyKE, M. (coord.), Gender and the Body in the Ancient Mediterranean, Oxford \& Malden, Blackwell Publishers, pp. 38-55; GuINAN, A.K. (2002), Erotomancy: Scripting the Erotic. En PARPOLA, S.W. (coord.), Sex and Gender in the Ancient Near East, Helsinki, The Neo-Assyrian Text Corpus Project, pp. 185-201.

50 Véase CoOper, J. (1997), Gendered Sexuality in Sumerian Love Poetry. En FinKel, I. L.; y Geller, M. J. (coord.), Sumerian Gods and their Representations, Groningen, Styx Publications, pp. 85-97, para una argumentación sobre la existencia de una voz femenina en la poesía amorosa sumeria. 
la función reproductiva de las mujeres como las que conciben, gestan y dan a luz, define y condiciona en gran medida su rol social.

En la serie Šumma sinništu qaqqada rabât, el cuerpo femenino se toma como un sistema de signos en el que se concentran las capacidades, peligros, $\mathrm{y}$ tendencias futuras de la vida de la mujer. El abanico de posibilidades que se representan ligados al cuerpo, sin embargo, son reducidos y aluden, como ya he expuesto, a facetas muy vinculadas al rol familiar, reproductivo, maternal, representando diversas fases o momentos vitales significativos: la entrada e integración de la mujer en el linaje del esposo, la potencialidad de ser madre, el embarazo, etc. Esta tendencia se muestra constante en lo que se refiere a la literatura profética ligada a la mujer en Mesopotamia, o, en palabras de KochWestenholz ${ }^{51}$, casi todas las profecías que aluden a las mujeres se refieren a aspectos sexuales y reproductivos de sus vidas.

Pero el «ser mujer» en Mesopotamia guarda muchas realidades en su interior. Con este artículo he intentado proporcionar, únicamente, una primera aproximación al estudio de la concepción del cuerpo femenino en el ámbito de la disciplina asiriológica.

Fecha de recepción: 26 de marzo de 2007

Fecha de aceptación: 15 de junio de 2007

51 Koch-Westenholz (2002), p. 303. 


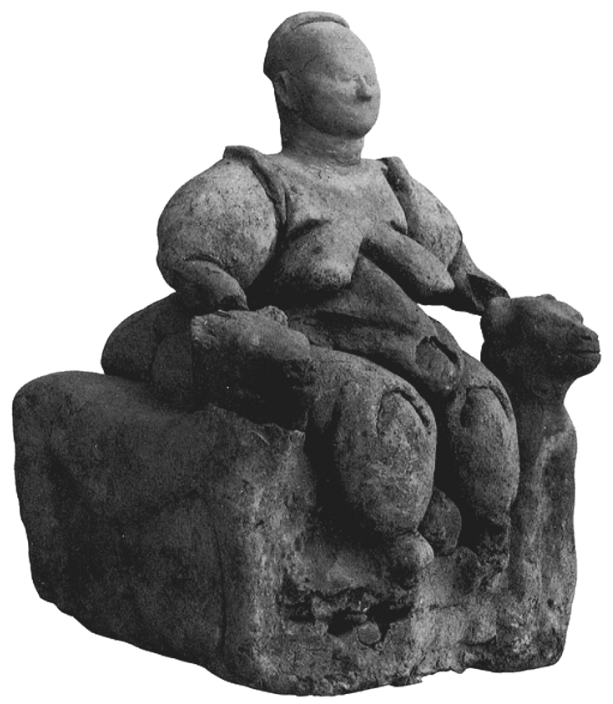

Figura 1: Figura femenina procedente de Çatal Hüyük, ca. 6500 a.e.c. Museo de Ankara

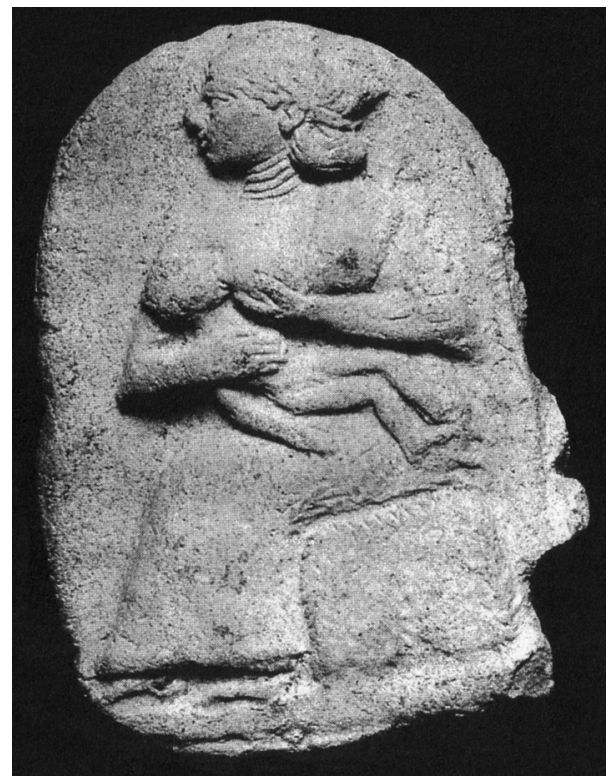

Figura 2: Imagen maternal, ca. 2100 a.e.c. BAHRANI (2002), p. 82. 